\title{
Farnesyl Protein Transferase
}

National Cancer Institute

\section{Source}

National Cancer Institute. Farnesyl Protein Transferase. NCI Thesaurus. Code C17526.

A heterodimeric enzyme (alpha and beta subunits) that catalyzes the addition of farnesyl groups, as farnesyl diphosphate, to the $\mathrm{C}$ termini of proteins. 